\title{
Therapeutic Options in Idiopathic Burning Mouth Syndrome: Literature Review
}

\author{
Ivan Miziara ${ }^{1}$ Azis Chagury ${ }^{1}$ Camila Vargas ${ }^{1}$ Ludmila Freitas $^{1} \quad$ Ali Mahmoud ${ }^{1}$ \\ ${ }^{1}$ Department of Otolaryngology, Universidade de São Paulo, \\ São Paulo, Brazil \\ Int Arch Otorhinolaryngol 2015;19:86-89. \\ Address for correspondence Azis Chagury, Department of \\ Otolaryngology, Universidade de São Paulo, Avenida Dr. Eneas de \\ Carvalho Aguiar, 155, São Paulo 05403-000, Brazil \\ (e-mail: azischagury@gmail.com).
}

\begin{abstract}
Keywords

- treatment

- stomatodynia

- burning mouth syndrome

Introduction Burning mouth syndrome (BMS) is characterized by a burning sensation in the tongue, palate, lips, or gums of no well-defined etiology. The diagnosis and treatment for primary BMS are controversial. No specific laboratory tests or diagnostic criteria are well established, and the diagnosis is made by excluding all other possible disorders.

Objective To review the literature on the main treatment options in idiopathic BMS and compare the best results of the main studies in 15 years.

Data Synthesis We conducted a literature review on PubMed/MEDLINE, SciELO, and Cochrane-BIREME of work in the past 15 years, and only selected studies comparing different therapeutic options in idiopathic BMS, with preference for randomized and double-blind controlled studies.

Final Comments Topical clonazepam showed good short-term results for the relief of pain, although this was not presented as a definitive cure. Similarly, $\alpha$-lipoic acid showed good results, but there are few randomized controlled studies that showed the longterm results and complete remission of symptoms. On the other hand, cognitive therapy is reported as a good and lasting therapeutic option with the advantage of not having side effects, and it can be combined with pharmacologic therapy.
\end{abstract}

\section{Introduction} and glossopyrosis, is characterized by a burning sensation with pain or itching, which may occur in the local tongue, palate, lips, and gums, with no etiology defined. ${ }^{1,2}$ Scala et al proposed that the BMS be classified into two clinical types ${ }^{3}$ : primary or essential/idiopathic BMS, for which local or systemic causes cannot be identified, and secondary BMS, which is due to organic causes, such as oral infections, autoimmune diseases of the oral mucosa (lichen planus), nutritional/vitamin deficiencies, allergies, irritation caused by reflux, candidiasis, diabetes mellitus, or administration of certain drugs. ${ }^{4,5}$

The epidemiology of BMS is still poorly described in the literature, with prevalence rates ranging from 15 to $0.7 \%$ of the general population. ${ }^{6}$ Symptoms are described more often in women aged around 40 to 60 years of age, near menopause,

received

March 6, 2014

accepted

April 15, 2014

published online

July 9, 2014
DOI http://dx.doi.org/

10.1055/s-0034-1378138. ISSN $1809-9777$.
Burning mouth syndrome (BMS), or glossalgia, stomatodynia, coexisting in strong association with psychological disorders such as anxiety and depression. ${ }^{7}$

The pathophysiology of BMS is not yet fully established. Several studies have shown significant differences in thermal nociception and the limits of patients with BMS compared with controls, ${ }^{8,9}$ demonstrating that there may be neuropathic changes involved. However, it is not known if the dysfunction is peripheral or central.

The diagnosis and treatment for primary BMS are controversial. There are no specific, well-established laboratory tests or diagnostic criteria, and the diagnosis is made by exclusion of all other possible disorders.

\section{Review}

We conducted a literature review on the main treatment options in idiopathic BMS and compared the best results of
Copyright $\odot 2015$ by Thieme Publicações License terms Ltda, Rio de Janeiro, Brazil 
the major studies in the previous 15 years. A literature review was performed on PubMed/MEDLINE, SciELO, and CochraneBIREME, using the terms "treatment and burning mouth syndrome" or "glossodynia and treatment."

Approximately 295 studies were described in the past 15 years, but only studies comparing different therapeutic options in idiopathic BMS, with preference for randomized controlled trials (RCTs), were selected. Studies with nonsignificant and/or nonstandard sample methodology were excluded. All studies included patients with idiopathic BMS along with continuous pain, and patients with organic causes were excluded. Thus, no abnormalities were found on physical or laboratory examination. The method of pain assessment in most studies was the visual analog score (VAS) with scores of 0 to 10 , where 0 is no pain and 10 is unbearable pain.

\section{Hypericum perforatum}

Hipericin is an herbal medicine used to relieve the symptoms of mild to moderate depression and associated symptoms such as anxiety, generalized muscle tension, and pain. In the literature, we found only the article by Sardella et $\mathrm{al}^{10}{ }^{10}$ which was a randomized, double-blind, placebo-controlled study conducted at a single center and studied 43 patients with BMS, dividing them into two groups. The first used Hypericum perforatum extract (hyperforin $0.31 \%$ and $3.0 \%, 900 \mathrm{mg} / \mathrm{d}$ ) and the second used placebo (control group) three times a day for 12 weeks. After 3 months of treatment, no significant improvement in symptoms were noted, and the main side effect was headache.

\section{Tongue Protector}

The parafunctional habit can contribute to pain in the oral cavity. Few articles were found in the treatment of BMS using the tongue protector. The single RCT found, by López-Jornet et al, divided 50 patients into two groups. Group A $(n=25)$ used only techniques of self-control and group B $(n=25)$ used self-control plus tongue protector (transparent polyethylene cover single size, used for 15 minutes, three times daily) for 2 months. ${ }^{11}$ The second group had better results with a statistically significant difference. However, the study had a small number of patients with little follow-up.

\section{Capsaicin}

Capsaicin, a component of peppermint, can bind TRPV1 (Transient Receptor Potential Vanilloid 1), a potent calcium receptor. When inactive, neuronal responses are linked to heat, thus prolonged exposure to capsaicin can deplete the TRPV1 in peripheral tissues, contributing to the long-term desensitization of peripheral nociceptors and consequently a reduction in the sense of ardor. ${ }^{12}$

Petruzzi et al analyzed 50 patients with BMS; 25 used systemic capsaicin $(0.25 \%)$ and 25 received a placebo for 30 days. ${ }^{12}$ Symptoms improved in $80 \%$ of patients using capsaicin; however, epigastric pain has been reported as a major side effect.

On the other hand, Marino and colleagues compared topical capsaicin $(250 \mathrm{mg} / 50 \mathrm{~mL}$ ), $\alpha$-lipoic acid (ALA) 800 $\mathrm{mg} / \mathrm{d}$, lactoperoxidase lysozyme, and placebo in the 56 patients divided equally between groups; symptoms improved in $76,57,57$, and $79 \%$, respectively. ${ }^{13}$ The study showed great results with no reported side effects, but the rate of placebo was close to the tested drugs.

More recent studies with topical $0.02 \%$ capsaicin also showed slight improvement, but with few significant results. ${ }^{14}$

\section{Clonazepam}

Clonazepam is a benzodiazepine that has an inhibitory effect on the central nervous system and is widely used as an anxiolytic agent.

Gremeau-Richard et al studied 48 patients with BMS, divided into topical clonazepam ( $3 \mathrm{mg} / \mathrm{d} ; n=24$ ) and placebo $(n=24)$, treated for 2 weeks. Results showed $72 \%$ improvement, with main side effects of xerostomia, sleepiness, and increased burning. $^{15}$

Another study by Rodríguez de Rivera Campillo et al evaluated 33 patients who received clonazepam $0.5 \mathrm{mg} / \mathrm{d}$, used for 3 minutes in the mouth without swallowing, and 33 placebo tablets used in the same way, with follow-up of 1 month and 6 months. ${ }^{16}$ Approximately $69 \%$ of those using clonazepam showed improvement of symptoms, and only $12 \%$ of controls had a positive response. However, regarding the cure of symptoms, the result was not significant in either group.

Amos et al conducted a study with the combination of topical ( $0.5 \mathrm{mg}$ tablets three times per day) and systemic (ingested the pills after a few minutes) clonazepam in 36 patients. ${ }^{17}$ After 6 months of treatment, 80\% achieved significant improvement in pain and 33\% had complete resolution of symptoms. However, there is need for further randomized studies to better assess the effects of this association.

In a more recent case-control study, Heckmann et al evaluated 20 patients with BMS for 9 weeks and separated into two groups. ${ }^{18}$ The clonazepam group $(n=10)$ took $0.5 \mathrm{mg} / \mathrm{d}$ and the other group took only placebo. There were no significant physiologic changes or improvement in the gustatory tests and salivary flow over time in both groups. However, pain was significantly reduced in the test group, and the study concluded that at low doses, the drug was more effective in younger individuals who with shorter time of illness.

With respect to potential predictors of the outcome of therapy with clonazepam, Ko et al evaluated 100 patients with BMS and suggested that the drug had a greater effect in patients with major salivary flow, patients who were more symptomatic, and patients who were not using psychotropic drugs. ${ }^{19}$

Despite the possible side effects that may occur at low doses, clonazepam has shown promising results for relief of symptoms.

\section{Cognitive Therapy}

Cognitive therapy, or psychotherapy, is emerging increasingly in the literature. Bergdahl et al showed improved symptoms with only cognitive therapy, with a significant difference from placebo. ${ }^{20}$ Subsequently, Femiano and colleagues studied therapy alone ( $2 \mathrm{~h} / \mathrm{wk}$ for 2 months), ALA (600 mg/d for 2 months), the combination of both (ALA and therapy), and placebo (control). ${ }^{21}$ The most important result was seen in the group using ALA + cognitive therapy, with complete resolution in 53\% and some improvement in $90 \%$. 
A more recent study by Komiyama et al studied 24 women with BMS who consulted with a dentist (20-minute lecture) and a neurologist (cognitive and behavioral therapy). ${ }^{22}$ The lecture was repeated after 6 months, and most patients showed improved graduation anxiety and, consequently, pain.

\section{Acupuncture}

Acupuncture is an ancient healing technique used for centuries in the treatment and prevention of diseases in China. Furthermore, it has been increasingly used in Western countries as an alternative method for treating pain. ${ }^{23}$

A systematic review examined Chinese articles that compared the treatment of BMS through acupuncture, and we selected nine relevant studies. ${ }^{24}$ In seven trials acupuncture showed a significant improvement in symptoms compared with the control. However, all studies have only been published in local magazines and had questionable methodologies.

\section{Aloe vera (Aloe barbadensis)}

Topical application of a combined Aloe vera (AV) can eliminate parafunctions that can protect the oral mucosa from repeated trauma and alleviate the symptoms of the BMS. In one study, López-Jornet used topical application of AV three times per day along with a tongue protector. ${ }^{25}$ The double-blind, randomized, case-control study lasted 12 weeks. Patients were divided into three groups: group I used a tongue protector alone, group II used AV and a tongue protector, group III used a tongue protector and placebo. Patients were homogeneous in terms of anxiety, and an improvement in VAS score was noted in all groups, but no significant difference was evident between groups in the category anxiety and quality of life, requiring more multicentric studies with treatment for longer periods.

\section{Catuama}

Catuama, an herbal product made in Brazil for over 20 years, is known for its revitalizing effects, with diminishment of physical and mental fatigue. Catuama is a mixture of four medicinal plants: Paullinia cupana (guarana), Trichilia catigua (Catuaba), Zingiber officinale (ginger), and Ptychopetalum olacoides (Muira Pauma). The combination of these four components showed antinociceptive, antidepressant, and vasorelaxing properties with involvement of the dopaminergic and serotonergic systems.

Spanemberg et al did a randomized, double-blind controlled study of 72 patients with BMS. ${ }^{26}$ The patients were divided into test group $(n=38)$ and controls $(n=34)$, and patients were instructed to take two capsules per day for 8 weeks. Following treatment, symptoms were reduced by $52.4 \%$ in the test group (VAS) and $24.2 \%$ in the control group, and these results remained stable until the end of the 12 weeks. One patient complained of drowsiness and weight gain and another, insomnia.

\section{o-Lipoic Acid}

ALA is an antioxidant able to scavenge free radicals, exerting activity in nerve repair. Femiano and Scully studied its effect in patients with BMS, who obtained better results than patients who received placebo. ${ }^{27,28}$ Likewise, López-D’alessandro and Escovich also showed superior results with the combination of ALA (600 mg/d) and $\gamma$-aminobutyric acid (300 $\mathrm{mg} / \mathrm{d})$, an anticonvulsant agent used for the treatment of peripheral neuropathy, with up to $70 \%$ improvement in symptoms associated with it. ${ }^{29}$

However, Cavalcanti and da Silveira used ALA $600 \mathrm{mg} / \mathrm{d}$ in 19 patients with BMS, and $89.9 \%$ of them achieved symptom improvement, but there was no significant difference between groups. ${ }^{30}$

In parallel, Carbone et al compared 18 patients who had been treated with ALA $(800 \mathrm{mg} / \mathrm{d}), 14$ patients treated with ALA (400 mg/d) and vitamins (twice a day), and 20 patients treated with placebo; no significant improvement was evident between groups. ${ }^{31}$ In a randomized clinical trial, LópezJornet et al compared ALA ( $400 \mathrm{mg} / \mathrm{d})$ and placebo and found no significant difference between groups. ${ }^{32}$

\section{Paroxetine}

Yamazaki et al performed a dose-dependent pilot study on the effect of paroxetine in the treatment of 52 patients with BMS. $^{33}$ By 12 weeks, patients received paroxetine 10 to $30 \mathrm{mg} / \mathrm{d}$ (dose adjusted to every 15 days according to symptoms, and $10 \mathrm{mg}$ each time) and domperidone to avoid side effects of nausea in the first 2 weeks. About $80 \%$ had improvement in pain after 12 weeks of treatment, with few reported side effects. Thus, the author proposes to start with $10 \mathrm{mg} / \mathrm{d}$ and increase by $10 \mathrm{mg}$ every 2 weeks, reaching a maximum up to $30 \mathrm{mg} / \mathrm{d}$ if the dose is insufficient. However, in this study there was no comparison with placebo.

\section{Discussion}

The treatment of patients with idiopathic BMS offers a wide variety of therapeutic options, from tongue protectors to drugs with restricted use. This broad diversity requires more studies to assess which treatment should be the gold standard for this common malady affecting the quality of life of people around the world.

In the literature, the use of $H$. perforatum was found in only one RCT, which did not show superiority to placebo. Likewise, we found only one RCT using a tongue protector for patients with BMS; however, López-Jornet et al used a limited number of patients and with little follow-up, proving no statistically benefit. $^{11}$

Capsaicin showed significant improvement of burning symptoms, but is not in systemic use in Brazil, and although collateral effects may limit its use, the topical presentation can be used as an alternative form of relief in the short term. This short-term symptom relief was also shown in studies involving clonazepam, ${ }^{17,18}$ which, despite possible collateral effects that may arise in high doses, can be part of the therapeutic strategy in these patients, mainly for shortterm pain relief.

Another nonpharmacologic treatment that has proven effective is cognitive therapy; in the studies of Femiano et $\mathrm{al}^{21}$ and Komiyama et $\mathrm{al}^{22}$ the results were promising 
and with the advantage of not having side effects that may often be associated with drug therapy.

The studies involving acupuncture, AV, Catuama, and paroxetine had statistically unsatisfactory results, requiring further RCTs for better evaluation.

Finally, ALA treatment had the most published studies. Femiano and colleagues, ${ }^{27,28}$ who initially began researching this treatment, found significant clinical improvement in their groups, but this result was not successfully replicated in the following studies, ${ }^{30,31}$ demonstrating the need for more randomized controlled studies that show long-term results and a complete remission of symptoms.

\section{Conclusion}

Although there are various forms of pharmacologic treatment for idiopathic BMS, there are no well-defined data and studies to formulate a consensus on this syndrome. It is necessary that in the future there is a systematic improvement in the diagnosis of these patients, including which patients will respond best to various lines of treatment available according to possible predictors of treatment response.

\section{References}

1 Grushka M, Epstein JB, Gorsky M. Burning mouth syndrome. Am Fam Physician 2002;65(4):615-620

2 Merskey H, Bugduk N. Task on Taxonomy. Seattle: Classification of Chronic Pain. Description of Chronic Pain Syndromes and Definition of Pain Terms. Seattle, WA: IASP Press; 1994

3 Scala A, Checchi L, Montevecchi M, Marini I, Giamberardino MA. Update on burning mouth syndrome: overview and patient management. Crit Rev Oral Biol Med 2003;14(4):275-291

4 Muzyka BC, De Rossi SS. A review of burning mouth syndrome. Cutis 1999;64(1):29-35

5 Minguez-Sanz MP, Salort-Llorca C, Silvestre-Donat FJ. Etiology of burning mouth syndrome: a review and update. Med Oral Patol Oral Cir Bucal 2011;16(2):e144-e148

6 Zakrzewska JM, Forssell H, Glenny AM. Interventions for the treatment of burning mouth syndrome. Cochrane Database Syst Rev 2005;25(1):CD002779

7 Bergdahl M, Bergdahl J. Burning mouth syndrome: prevalence and associated factors. J Oral Pathol Med 1999;28(8):350-354

8 Ito M, Kurita K, Ito T, Arao M. Pain threshold and pain recovery after experimental stimulation in patients with burning mouth syndrome. Psychiatry Clin Neurosci 2002;56(2):161-168

9 Albuquerque RJ, de Leeuw R, Carlson CR, Okeson JP, Miller CS, Andersen AH. Cerebral activation during thermal stimulation of patients who have burning mouth disorder: an fMRI study. Pain 2006;122(3):223-234

10 Sardella A, Lodi G, Demarosi F, Tarozzi M, Canegallo L, Carrassi A. Hypericum perforatum extract in burning mouth syndrome: a randomized placebo-controlled study. J Oral Pathol Med 2008; 37(7):395-401

11 López-Jornet P, Camacho-Alonso F, Andujar-Mateos P. A prospective, randomized study on the efficacy of tongue protector in patients with burning mouth syndrome. Oral Dis 2011;17(3): 277-282

12 Petruzzi M, Lauritano D, De Benedittis M, Baldoni M, Serpico R. Systemic capsaicin for burning mouth syndrome: short-term results of a pilot study. J Oral Pathol Med 2004;33(2):111-114

13 Marino R, Torretta S, Capaccio P, Pignataro L, Spadari F. Different therapeutic strategies for burning mouth syndrome: preliminary data. J Oral Pathol Med 2010;39(8):611-616
14 Silvestre FJ, Silvestre-Rangil J, Tamarit-Santafé C, Bautista D. Application of a capsaicin rinse in the treatment of burning mouth syndrome. Med Oral Patol Oral Cir Bucal 2012;17(1):e1-e4

15 Gremeau-Richard C, Woda A, Navez ML, et al. Topical clonazepam in stomatodynia: a randomised placebo-controlled study. Pain 2004;108(1-2):51-57

16 Rodríguez de Rivera Campillo E, López-López J, Chimenos-Küstner E; Rodríguez de RCE. Response to topical clonazepam in patients with burning mouth syndrome: a clinical study. Bull Group Int Rech Sci Stomatol Odontol 2010;49(1):19-29

17 Amos K, Yeoh SC, Farah CS. Combined topical and systemic clonazepam therapy for the management of burning mouth syndrome: a retrospective pilot study. J Orofac Pain 2011;25(2):125-130

18 Heckmann SM, Kirchner E, Grushka M, Wichmann MG, Hummel T. A double-blind study on clonazepam in patients with burning mouth syndrome. Laryngoscope 2012;122(4):813-816

19 Ko JY, Kim MJ, Lee SG, Kho HS. Outcome predictors affecting the efficacy of clonazepam therapy for the management of burning mouth syndrome (BMS). Arch Gerontol Geriatr 2012;55(3): 755-761

20 Bergdahl J, Anneroth G, Perris H. Cognitive therapy in the treatment of patients with resistant burning mouth syndrome: a controlled study. J Oral Pathol Med 1995;24(5):213-215

21 Femiano F, Gombos F, Scully C. Burning Mouth Syndrome: open trial of psychotherapy alone, medication with alpha-lipoic acid (thioctic acid), and combination therapy. Med Oral 2004;9(1):8-13

22 Komiyama O, Nishimura H, Makiyama Y, et al. Group cognitivebehavioral intervention for patients with burning mouth syndrome. J Oral Sci 2013;55(1):17-22

23 Kaptchuk TJ. Acupuncture: theory, efficacy, and practice. Ann Intern Med 2002;136(5):374-383

24 Yan Z, Ding N, Hua H. A systematic review of acupuncture or acupoint injection for management of burning mouth syndrome. Quintessence Int 2012;43(8):695-701

25 López-Jornet P, Camacho-Alonso F, Molino-Pagan D. Prospective, randomized, double-blind, clinical evaluation of Aloe vera Barbadensis, applied in combination with a tongue protector to treat burning mouth syndrome. J Oral Pathol Med 2013;42(4):295-301

26 Spanemberg JC, Cherubini K, de Figueiredo MA, Gomes AP, Campos MM, Salum FG. Effect of an herbal compound for treatment of burning mouth syndrome: randomized, controlled, double-blind clinical trial. Oral Surg Oral Med Oral Pathol Oral Radiol 2012; 113(3):373-377

27 Femiano F, Gombos F, Scully C, Busciolano M, De Luca P. Burning mouth syndrome (BMS): controlled open trial of the efficacy of alpha-lipoic acid (thioctic acid) on symptomatology. Oral Dis 2000;6(5):274-277

28 Femiano F, Scully C. Burning mouth syndrome (BMS): double blind controlled study of alpha-lipoic acid (thioctic acid) therapy. J Oral Pathol Med 2002;31(5):267-269

29 López-D'alessandro E, Escovich L. Combination of alpha lipoic acid and gabapentin, its efficacy in the treatment of Burning Mouth Syndrome: a randomized, double-blind, placebo controlled trial. Med Oral Patol Oral Cir Bucal 2011;16(5):e635-e640

30 Cavalcanti DR, da Silveira FR. Alpha lipoic acid in burning mouth syndrome-a randomized double-blind placebo-controlled trial. J Oral Pathol Med 2009;38(3):254-261

31 Carbone M, Pentenero M, Carrozzo M, Ippolito A, Gandolfo S. Lack of efficacy of alpha-lipoic acid in burning mouth syndrome: a double-blind, randomized, placebo-controlled study. Eur J Pain 2009;13(5):492-496

32 López-Jornet P, Camacho-Alonso F, Leon-Espinosa S. Efficacy of alpha lipoic acid in burning mouth syndrome: a randomized, placebo-treatment study. J Oral Rehabil 2009;36(1):52-57

33 Yamazaki Y, Hata H, Kitamori S, Onodera M, Kitagawa Y. An openlabel, noncomparative, dose escalation pilot study of the effect of paroxetine in treatment of burning mouth syndrome. Oral Surg Oral Med Oral Pathol Oral Radiol Endod 2009;107(1):e6-e11 